\title{
UMA PERSPECTIVA CRÍTICA DO DIREITO PENAL CONTEMPORÂNEO E AS POSSIBILIDADES DE UM DIREITO PENAL MÍNIMO
}

\author{
Ana Luisa Silva Robazzi \\ Graduanda do $4^{\circ}$ ano de Direito \\ e-mail: anarobazzi@pop.com.br
}

Fábio Henrique Esposto

Graduando do $4^{\circ}$ ano de Direito

e-mail: fabioesposto@hotmail.com

RESUMO: Na tentativa de conter a violência e a insegurança que pairam, medidas repressivas são discutidas e requisitadas. Porém, sabemos que o Estado seleciona os punidos entre as pessoas menos abastadas. Dessa forma, há um grande hiato entre os delinqüentes de fato e os punidos. Assim, é falha a identificação do criminoso com o encarcerado, já que a maior parte dos criminosos não vai para a prisão, sendo recrutado, para tanto, um perfil seleto de infratores, qual seja: pobres e, em sua maioria, negros. No que tange à elaboração das Leis, são concedidos privilégios a certas classes. Não bastasse isso, possuímos um Código Penal extremamente moralista, que pretende invadir a esfera de liberdade do indivíduo. Ademais, o Código é abusivamente patrimonialista, valorizando mais o patrimônio que a vida. Note-se que tais medidas não atacam as causas da criminalidade, oriundas principalmente da desigualdade social, mas tão-somente seus efeitos. Defendemos a minimização do Direito Penal, de forma que atue somente quando sejam ofendidos bens jurídicos fundamentais e com caráter subsidiário, até mesmo para fortalecê-lo. Destarte, construir mais cadeias, como vem sendo proposto, e não se investir nos direitos básicos da população pode até render votações e dar a impressão de que se está resolvendo o problema, mas não ajudará na solução, já que esta perpassa por outros problemas que vão além da elaboração de Leis.

PALAVRAS-CHAVE: Punição seletiva; Cifra oculta; Etiquetamento; Discriminação; Hipertrofia do direito penal; Direito penal mínimo. 
Atualmente, a sociedade brasileira vive em um período de clamor por repressão, devido aos altos índices de criminalidade que facilmente verifica pela televisão e no seu cotidiano. Na tentativa desesperada de conter a violência e a grande insegurança que paira, medidas repressivas são discutidas e requisitadas.

Grande parte da sociedade passa a acreditar que só a aplicação rígida do Direito Penal é capaz de desestimular o cometimento de crimes por meio do medo da pena que virá como punição. Na ânsia de resolver este problema, retoma-se o debate sobre temas como a pena de morte, a prisão perpétua e a diminuição da maioridade penal, não atentando para as garantias e direitos individuais, mesmo diante do dispositivo constitucional que afirma que não poderá ser objeto de emenda a abolição dos direitos e garantias individuais (art. 60, \$ 4ํㅗ IV, da Constituição Federal).

No que tange à elaboração legal, o Legislativo, com uma retórica firme e a ajuda da mídia para moldar a subjetividade ${ }^{1}$ dos cidadãos, ${ }^{2}$ produz leis com penas cada vez maiores, como a lei 8.072/90, denominada Lei dos Crimes Hediondos. Além disso, tem-se como bom o processo que condena e faz prevalecer o ius puniendi do Estado em detrimento do ius libertais do indivíduo, desrespeitando a relação de equilíbrio que deve haver entre os dois institutos.

Assim, ao se formularem Leis mais duras ataca-se apenas os efeitos da criminalidade, combatendo a violência com mais violência. É fato que tal hipertrofia na produção de Leis não contribui efetivamente para a diminuição da criminalidade, haja vista que o problema parece estar ligado a outros motivos.

Note-se que as causas da criminalidade, oriundas principalmente da desigualdade social, não são atacadas. Pelo contrário, são constantemente reafirmadas pela distribuição e pela execução orçamentárias, que privilegiam gastos

${ }^{1}$ Subjetividade, aqui, pode ser entendida como "as diferentes formas através das quais o sujeito pensa, sente, deseja e representa a si mesmo e ao mundo que o cerca". SOUZA, Mériti de. A Experiência da Lei e a Lei da Experiência. Rio de Janeiro: Editora Revan, 1999, p.18. APUD: PRADO, Geraldo. Elementos para uma Análise Crítica da Transação Penal. Rio de Janeiro: Lumen Juris, 2003, p.67.

2 Vide Linha Direta, Cidade Alerta e outros programas do gênero, que ,ao colocarem o medo no ar, ajudam na argumentação de que são necessárias normas mais repressivas, ainda que em detrimento de alguns direitos. 
de fundos meramente econômicos, em detrimento de programas sociais nas áreas de saúde, educação, cultura etc. ${ }^{3}$

Nesse ínterim, vivemos sob a égide da ideologia da "lei e ordem", segundo a qual passamos a ser todos criminosos. Condutas como comprar um CD ou DVD pirata, responder à chamada para um colega ausente, passar num sinal vermelho, dirigir embriagado, sonegar impostos, utilizar drogas ilegais, cometer adultério, utilizar atestado médico falso etc.; são tipificadas como crimes. Assim, fica nítido que ao se conceituar criminoso como aquele que pratica conduta tipificada nas leis penais, somos todos criminosos. Porém, sabemos que o Estado pune selecionando sua clientela entre as pessoas menos abastadas, daí termos cerca de "...noventa e cinco por cento dos presos pertencentes à classe social mais baixa", ${ }^{4}$ enquanto 0 cometimento de delitos advém de todas as classes sociais, inclusive da mais alta, com os "crimes de colarinho branco".

Essa seletividade acaba por gerar um "etiquetamento" em tais pessoas. Etiquetamento, porque ao nos perguntarmos quem é bandido, nossa subjetividade nos dirá que é quem está na cadeia, e ao olharmos para a cadeia, veremos as pessoas que são etiquetadas (que se amoldaram às condutas descritas) e que acima de tudo foram selecionadas para estarem presas, quais sejam, os pobres, notadamente os negros.

Dessa forma, há um grande hiato entre os delinqüentes de fato e os punidos, principalmente quando tais delinqüentes são pessoas provenientes das classes sociais mais abastadas.

Note-se que há várias fases entre o cometimento do delito e a efetiva punição do mesmo com uma pena privativa de liberdade, sendo que, em cada uma dessas etapas, um grande número de "criminosos" deixa de sofrer punição, não entrando nas estatísticas oficiais.

Primeiramente, devemos considerar que a ocorrência de muitos delitos não chega ao conhecimento da autoridade policial, vez que as vítimas não levam a noticia criminis até o órgão coator. Um caso muito freqüente que se encaixa nesta

${ }^{3}$ A fácil - e enganosa - solução de editar Leis penais ou de se Ihes aumentar o rigor, especialmente num quadro agudo de profundas desigualdades sociais, há de preferir e prestigiar, antes, o homem, o trabalho, a educação, a assistência social, a assistência à família etc., criando condições mínimas para evitar a desintegração da família e a marginalização do homem, e para cuja solução o sistema penal, chamado a intervir, acaba, contrariamente, não raras vezes, por os agravar e os recrudecer. QUEIROZ. Paulo de Souza. Do caráter subsidiário do direito Penal: lineamentos para um direito penal mínimo. Belo Horizonte: Del Rey, 2. Ed. 2002.

${ }^{4}$ THOMPSON, Augusto. Quem são os criminosos?. Rio de Janeiro: Lúmen Júris, 1998. p.32. 
hipótese é o das mulheres que sofrem agressões físicas, psicológica ou até sexuais dos maridos e que não os denunciam. ${ }^{5}$

Há ainda os casos em que o Inquérito Policial nem sequer é aberto, pelo fato de o Delegado de Polícia considerar desnecessária a sua instauração. Mesmo quando há a instauração do Inquérito, por vezes o Promotor de Justiça não oferece a denúncia que iniciaria a ação penal, ficando mais uma vez fora das estatísticas os infratores envolvidos. Ademais, existem as hipóteses que se enquadram nas previsões da Lei dos Juizados Especiais (9099/95), em que há conciliação, transação penal ou suspensão condicional do processo, sem que haja 0 prosseguimento da ação penal. ${ }^{6}$

Restam ainda: os infratores que são absolvidos, aqueles que são condenados a penas não restritivas de liberdade, bem como os que cumprem pena em liberdade.

Dessa forma, fica evidente uma "cifra oculta" da criminalidade gerada pela diferença entre os que são presos e os que praticaram delitos, estes em número excepcionalmente maior. Logo, é falha a identificação do criminoso com o encarcerado, já que a maior parte dos criminosos não vai para a prisão, sendo recrutado para tanto um perfil seleto de infratores, qual seja: pobres e, em sua maioria, negros.

No que tange à elaboração das Leis, percebe-se também uma grande discriminação, com tendência a conceder privilégios a certas classes. Um exemplo que demonstra tal afirmação é a Lei 9.249/95, que, em seu art. 34, prevê a extinção da punibilidade quando o agente promover o pagamento do tributo ou contribuição social, inclusive acessórios, antes do recebimento da denúncia nos crimes definidos nas Leis 8.137/90 e 4.729/65 (Sonegação Fiscal e Contra a Ordem Tributária, Econômica e Relações de Consumo).

Válido frisar que tais crimes lesam milhares de pessoas, bem como direitos transindividuais e coletivos, enquanto o crime de Furto não pressupõe o mesmo

\footnotetext{
${ }^{5}$ Note-se que o artigo 129, que trata de lesão corporal, prescreve que deve haver a representação da vítima para a instauração da ação penal, o que foi mudado com a reforma penal de 1984, vez que, até essa reforma, a ação era pública incondicionada, não necessitando assim o promotor da reclamação da esposa para instaurar a ação em caso de agressão pelo marido.

${ }^{6}$ Uma crítica contundente à Lei 9.099/95 é encontrada no livro de Geraldo Prado, em seu "Elementos para uma Análise Crítica da Transacão Penal." Rio de Janeiro: Editora Lúmen Juris, 2003.
} 
tratamento, caso o agente devolva o objeto do delito, sendo a devolução apenas causa de arrependimento posterior (art. 14, CP), que possibilita uma redução na aplicação da pena.

Diante disso, quem lesa apenas um cidadão, sem violência nem grave ameaça, e que devolve o objeto do furto, é punido, enquanto quem lesa milhões de pessoas desviando o dinheiro público é perdoado, desde que pague o valor desviado antes do recebimento da denúncia. Tais aberrações legislativas vêm gerando questionamentos por parte dos práticos e teóricos do direito, como Lênio Streck, que, ao questionar o princípio da isonomia em tais casos, propôs que

os benefícios concedidos pela Lei Penal aos delinqüentes tributários (Lei n. 9248/95, art. 34) alcançam os delitos patrimoniais em que não ocorra prejuízo nem violência, tudo em atenção ao principio da isonomia. Recurso provido para absolver o apelante ${ }^{7}$

Outro exemplo gritante de violação do princípio da isonomia é o previsto no art. 295, inciso VII, do Código de Processo Penal que prevê prisão especial para aqueles que possuem diploma de curso universitário, sem nenhuma razão plausível, a não ser privilegiar indivíduos que tiveram a oportunidade de estudar em uma universidade. É importante ressaltar que tal norma é infraconstitucional e afronta um princípio constitucional, não atentando para a hierarquia na aplicação das normas.

Não bastasse isso, possuímos um Código Penal extremamente moralista, que pretende invadir a esfera de liberdade do indivíduo. Como exemplo desse moralismo podemos citar o crime de adultério, art. 240, ou o de "manter casa de prostituição", art. 227, sedução, art. 217; condutas que não deixam de existir pelo fato de estarem normatizadas. Também é precípuo notar que são definidos "bons costumes", padrões de comportamento, critérios para a classificação da "personalidade" e "periculosidade" de um indivíduo; de acordo com a ideologia da classe dominante. Se notamos que existem condutas que pouco ou em nada lesam a esfera do outro e que estas são criminalizadas, não há outra explicação para a tipificação de tais atos sem ser a vontade de controlar as ações dos indivíduos. Neste viés, o Direito Penal é utilizado como instrumento para a imposição da ideologia dominante sobre as classes exploradas, visando padronizar comportamentos para garantir a "lei e a ordem" e a "paz social" da dominação, é claro.

\footnotetext{
${ }^{7}$ Apelação-Crime n. 297.019.937, decisão de 25 de setembro de 1997.
} 
Ademais, o código é abusivamente patrimonialista, valorizando mais o patrimônio que a vida. Prova disso é o art. 129, que disciplina a lesão corporal, conceituada como "ofender a integridade corporal ou a saúde de outrem". Assim, se

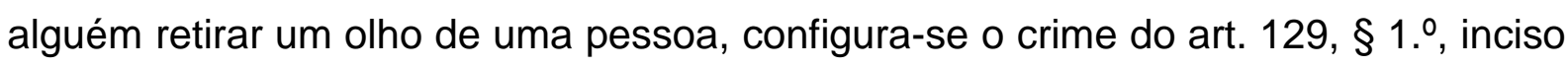
III com "debilidade permanente de membro, sentido ou função", sendo a pena de 1 a 5 anos e reclusão, enquanto quem se encaixar no art. 155, do mesmo código, que disciplina o furto "Subtrair, para si ou para outrem, coisa alheia móvel", quebrando por exemplo, uma porta, terá uma pena de 2 a 8 anos.

Outro exemplo que mostra o direcionamento das leis penais é o crime descrito no artigo 149 , que trata sobre a redução de alguém à condição análoga à de escravo, sendo prevista pena de 2 a 8 anos de reclusão, enquanto o crime de extorsão mediante seqüestro, previsto no art. 159, que se consuma ao "seqüestrar pessoa para obter, para si ou para outrem, qualquer vantagem, como condição ou preço de resgate", tem pena de 12 a 20 anos se o seqüestro durar mais de 24 horas. Assim, quando alguém é reduzido à condição análoga à de escravo, o que pressupõe um lapso de tempo considerável, em que o indivíduo tem sua liberdade tolhida, temos pena de 2 a 8 anos, já quando se seqüestra por 24 horas, a pena é de 12 a 20 anos. Fica no ar o questionamento sobre quem sofreria extorsão mediante seqüestro (note-se que a pena foi aumentada logo após o seqüestro de Abílio Diniz, o famoso dono do Pão de Açúcar, do Compre Bem e de outros supermercados).

Note-se que a seletividade na aplicação é sempre existente. Podemos citar, para ilustrar, passagens de Augusto Thompson, em seu livro "Quem são os criminosos?", que mostrou que dois garotos quebraram portas de vestiário de clube e subtraíram tênis alheio, o que se caracterizaria como crime, mas, na hora da punição, o diretor chamou os pais dos infratores e os mandou para a casa, pois estavam apenas fazendo brincadeira de mal gosto, enquanto no mesmo momento dois pobres que furtaram uma bolsa de alguém transitando na rua recebiam a pena em comento.

Imprescindível não esquecer que o Código Penal é de 1942, e a nossa Constituição, que é a norma máxima, é de 1988, sendo que vários crimes tipificados no Código padecem de inconstitucionalidade, por não terem sido receptados pela nova carta. 
Assim, é precípuo que haja uma filtragem constitucional na aplicação das leis, já que a Constituição é a norma fundante das outras, dando validade para as normas hierarquicamente inferiores. Nas palavras de Lênio Streck. "No quadro da interpretação conforme a Constituição, normas constitucionais são, portanto, não só 'normas de exame', mas também 'normas materiais' para a determinação do conteúdo de leis ordinárias". (STRECK, Lênio. Hermenêutica Jurídica e $(\mathrm{m})$ crise: uma exploração hermenêutica na construção do Direito. Porto Alegre: Livraria do Advogado, 2004. p.252).

Devem as leis respeitar, dentre outros, tais princípios: o da necessidade (as condutas só devem ser tipificadas, e as penas aplicadas, quando necessárias para a vida em coexistência); e lesividade (só se deve criminalizar condutas que ofendam bens jurídicos, já que o DP não deve ser instrumento de moralização da sociedade). Daí não ser correta a tipificação de porte de entorpecente, já que o indivíduo lesa somente a si próprio, bem como as medidas de segurança, que não lesam, em grande proporção, nenhum bem jurídico. Tais condutas devem ser punidas por outros ramos do direito, como o administrativo ou o civil, já que a liberdade é direito público fundamental do indivíduo, mormente nos Estados liberais, ditos democráticos de direito. Contudo, o "senso comum teórico dos juristas"8 não enxerga, por ignorância, ou por má-fé, que algumas condutas devem ser descriminalizadas.

Por fim, defendemos a minimização do Direito Penal, atuando esse somente quando sejam ofendidos bens jurídicos fundamentais e com caráter subsidiário, até mesmo para fortalecê-lo.

Com a descriminalização das normas que não ofendam bens jurídicos fundamentais e as que ofendam sem intensidade alguma (princípio da irrelevância), não significa que se estará retirando o caráter ilícito de algumas condutas, mas estar-se-á tão-somente não impondo pena privativa de liberdade à conduta, vez que o direito penal deve ter um caráter subsidiário, sendo aplicado somente quando não haja outro jeito de se resolver o problema por outros ramos do direito.

Pensamos que o Estado deve investir nas causas do problema da criminalidade, que são a falta de direitos básicos garantidos na Constituição Federal, mas não efetivados, como direito à moradia, educação, saúde, vida digna (art. 6). Os

\footnotetext{
${ }^{8}$ Conceituação de Luis Alberto Warat.
} 
recursos que são utilizados na repressão seriam melhor aproveitados se utilizados na prevenção, uma vez que o custo dos presos é alto e que, no fim, acaba-se atacando a causa sem, contudo, atacar o efeito.

Destarte, construir mais cadeias como vem sendo proposto e não se investir nos direitos básicos da população pode até render votações e dar a impressão de que se está resolvendo o problema, mas não ajudará na solução, já que esta perpassa por outros problemas que vão além da elaboração de leis.

\section{BIBLIOGRAFIA}

BATISTA, Nilo. Introdução crítica ao direito penal brasileiro. Rio de Janeiro: Revan, 1990.

CARVALHO. Salo de. Pena e Garantias. 2. ed. Rio de Janeiro: Editora Lúmen Juris, 2003.

DORNELLES, João Ricardo W. O que é crime. 2. ed. São Paulo: Brasiliense, 1992, 84 p. (Coleção primeiros passos: 207)

FERRAJOLI, Luigi, Direito e Razão: Teoria do Garantismo Penal. Trad. Ana Paula Zomer e outros: São Paulo: Revista dos Tribunais, 2002.

LIRA FILHO, Roberto. Criminologia dialética. Rio de Janeiro: Borsoi, 1972.

MIR PUIG, Santiago. Función de la pena y teoria del delito em el estado social y democrático de derecho. 2. ed. Barcelona: Bosch, 1982.

MIAILLE, Michel. Introdução Crítica ao Direito. Lisboa: Editorial Estampa, 1989.

PRADO, Geraldo. Elementos para uma Análise Crítica da Transacão Penal. Rio de Janeiro: Editora Lúmen Juris, 2003.

QUEIROZ, Paulo de Souza. Do caráter subsidiário do direito penal: lineamentos para um direito penal mínimo. 2.ed. rev. e atual. Belo Horizonte: Del Rey, 2002.

ROXIN, Claus. Política criminal e sistema jurídico-penal. Trad. Luís Greco. São Paulo: Renovar, 2000. SANTOS, Juarez Cirino dos. As raízes do crime. São Paulo: Forense, 1984.

THOMPSON. Augusto. Quem são os Criminosos? - O Crime e o Criminoso: Entes Políticos. Rio de Janeiro: Lumen Júris,1998.

WACQUANT, Loic. Punir os pobres: a nova gestão da miséria nos estados unidos.

ZAFFARONI, Eugenio Raúl. Em busca de las penas perdidas: deslegitimación y dogmática jurídicopenal. Bogotá: Temis, 1990. 